\title{
T. A. Mason
}

This matter arises for me as a weight lifter since 1924, with a long record of youth work, because the Governing Body for Weight Lifting recently held a "schoolboys' Championship" on the three Olympic Lifts for lads of 14 to 16 years of age.

On the general question of whether young people should do weight lifting or weight training, my instinct is to say I prefer youngsters under, say 17 to 18 , not to specialise, but to do all-round physical recreation. This could include some of the exercises used in weight training but the movement and poundages used would have to be chosen carefully and the exercises well supervised.

I think that certain movements should be definitely ruled out: and, foremost among these I would name "The two hands clean and press (with barbell)". (prior to 1952 this was known as "The two hands clean and military press".) During the press, any deviation of the trunk from the upright position ruled out the lift. Under the new and very imprecise definition, the trunk is allowed by most referees, to assume a position of great hyperextension.

In Physical Education it has, I believe, long been accepted that "the development of the back is the essential point in the physical development of the whole body" - that the spine "lying hidden in the mid-line of the trunk, is the centre for all our movements and forms the basis and the starting point for them". (Knudson, 1920). Correct weight lifting movements can do this very well indeed.

The spinal mechanism is made to work very strongly in almost all weight lifting movements but even more so in movements above the head, and it is most desirable that such movements should be done within the laws of correct body mechanisms; that joints do not work at the extreme of motion.

One of the best expositions of the correct use of the spine is that of Goldthwait, Brown, Swain \& Kuhns 1952. The authors refer to mechanical and functional differences between various spinal segments and the danger to articular processes and spinous processes in maintaining a lordatic position. Dr. Troup also brought in the question of impingement of spinous processes in his paper. Goldthwaite, et. al. (1952) state the possibility that in extreme lumbar lordotic curves the spinous processes may act as fulcra with likely subluxation of the joints of the articular processes. This view is supported by a great number of authorities such as Williams (1939), Williams \& Worthington (1957), Wells (1960), Taylor (1962), Rasch \& Burke (1963), Munrow (1963) and Fait (1966). Munrow (1966) particularly referred to dangers inherent in the Olympic Press as it 
is now performed by adults. The movement as such was condemned by many other medico/surgical authorities as dangerous in both long and short terms. I submit if this is true for adults it is even more dangerous for growing youth.

I think it is agreed almost universally that the vertebrae do not fully ossify until the 20's - (one authority even gives as late an age as 24). Breckenridge \& Vincent (1965) say "the spine grows until the late twenties". It is my submission that this style of pressing place and undesirable tension on growing spines and should be forbidden or discouraged in lads of 14 to 16 years.

Any joint is vulnerable when it is, used at its extreme of motion and in most Presses done nowadays it is so. There is little or no room to manoeuvre if anything goes wrong at this extreme.

There is an undesirable degree of shear stress over the spinal joints with unequal pressure on the exterior, or rear part of the intervertebral disc. The apophyseal joints are used, in effect, as fulcra. The weight line does not go via the bodies and discs of the vertebra.

The human vertebra is not well suited for load bearing in any other position than its most stable one, with the back "straight" or, more accurately, maintaining the normal physiological curves of the spine.

I do not consider it essential to be establish actual cases of injury (although I fear the records of G.P's and the appropriate hospital departments have had them) but to show that the possibility exists.

It is $3 \frac{1}{2}$ years since this idea of Schoolboy Championships was mooted, and I, at least, have been in correspondence with the Department of Education and Science ever since giving much evidence, as I have quoted, that they should not be held. Nevertheless, they were held. I have seen no published report as to the medical examination of the lads competing but I believe a member of this Association attended with a newspaper photographer, and he had already commented upon them.

Other questionable movements are (i) the exercise known as the Two Hands Stiff-Legged Dead Lift, and (ii) the Two Hands Dead Left as recently defined.

In (i) it is a movement which has received almost universal condemnation especially in the industrial field. It places undue strain on the spinal msculature. In (ii) the lifter, by losing the privilege of resting the weight on the knees when halfway and re-aligning his spine, has very often to finish off the lift by action of the upper spinal muscles, whereas the trunk should stay upright throughout the lift for full safety. 
Breckenbridge, M.E. \& Vincent, E.L. (1965) "Child development ". Philadelphia, W. B. Saunders Co.

Fait, H.F. (1966) "Special Physical Education". Philadelphia, W.B.Saunders Co.p.278

Goldthwait, J.E. Brown, L.T., Swain, L.T., Kuhns, J.G. (1952). "Essentials of body mechanics in health and disease". Philadelphia, J.B. Lippincott Co.

Knudson, K.A. (1920) "Textbook of Gymnastics, Vol. 1. London, Heinemann, pp. 26 and 71.

Munrow, A.D. (1963a) "Pure and applied gymnastics", London, Arnold pp. 117 and 137 .

Munrow, A.D. (1963b). Personal communication.

Rasch, P.J. \& Burke, R.K. (1963)"Kinesiology and applied anatomy". Philadelphia, Lea \& Febiger.

Taylor, E. (1962) Training with weights" London J. Murrey. Wells, K.F. (1960) "Kinesiology" Philadelphia, W.B. Saunders Co. Williams, J.F. (1939)"Principles of Physical Education" Philadelphia, W.B. Saunders Co을 Williams, M. \& Worthington C. (1957) "Therapeutic Exercise for body ailment and function". Philadelphia, W.B. Saunders Co.

BOOK REVIEW

BRAIN DAMAGE IN BOXERS

A. H. Roberts

Pitman Medical $£ 1.50$

This is one of the most important contributions to the literature of Sport Medicine of its decade. Its significance lies less in its subject, important in its limited way as this may be, but in its demonstration of a completely objective and precise approach to the problem. Dr. Roberts is clearly aware of the limitations of his study (the fact that it is not fully representative, that it is retrospective) and draws his conclusions well within those limits, indicating with almost dramatic clarity the natural history of Boxers ' Encephelopathy with an absence of deliberate emphasis that sets his work apart from that of most other authors in the same field. Indeed, unlike such authors $\mathrm{Dr}$. Roberts has clearly not set out to prove a point but simply to observe and record. To some therefore this book will prove a disappointment providing as it does a little but only a little ammunition for both antagonists and protagonists of boxing alike. For the majority however it confirms unequivocally what most of us suspected anyway but will, it is to be hoped, stand as a yardstick against which all future utterances on the subject may be measured. This book should find a home on the shelves of all students of Sports Medicine. 